\title{
Event-Related Brain Potentials (ERPs) Elicited by Novel Stimuli during Sentence Processing ${ }^{a}$
}

\author{
MARTA KUTAS AND STEVEN A. HILLYARD \\ Department of Neurosciences \\ School of Medicine \\ University of California at San Diego \\ La Jolla, California 92093
}

Event-related brain potentials (ERPs) have proven to be particularly sensitive indices of the brain's response to unexpected, surprising, or deviant stimuli (for reviews see Donchin et al., 1978; Picton et al., 1979). One of the more prominent of these ERPs following "surprising" stimuli has been a late positive wave called the $\mathrm{P}_{3}, \mathrm{P}_{300}$ or late positive complex (LPC). Among other hypotheses, it has been proposed that the $\mathrm{P}_{300}$ may reflect the resolution of prior uncertainty (Sutton et al., 1965; Ruchkin and Sutton, 1978) and the task-relevant surprise value of the stimulus (Donchin et al., 1978). However, in some situations stimuli having no assigned task relevance, when presented infrequently and unexpectedly, have also been found to elicit enlarged late positive waves in the 200-500 ms range (Ritter et al., 1968; Roth, 1973; Courchesne et al., 1975; Squires et al., 1975; Roth et al., 1976; Snyder and Hillyard, 1976; Courchesne et al., 1978; Squires et al., 1977). These ERPs vary in waveform, amplitude, and scalp distribution, and it is not clear how many varieties of late positive waves may exist. Nonetheless, the general consensus has been that an unexpected event is typically followed by a $\mathrm{P}_{300}$ complex (often in association with an earlier $\mathrm{N}_{2}$ or $\mathrm{N}_{200}$ and a subsequent slow wave).

In contrast, recent experiments on ERPs to words in sentences have indicated that not all unexpected events are associated with a P300 complex (Kutas and Hillyard, $1980 \mathrm{a}, \mathrm{b})$. Thus, while a late parietal positivity followed an unexpected change in the size of the printed word at the end of a sentence, a large centro-parietal negative wave $(\mathrm{N} 400)$ followed semantically deviant words at the ends of these sentences. The present study was designed to find out whether physically deviant visual stimuli that were even more aberrant in the context of these sentences would be associated with a P300-like wave or with an $\mathrm{N} 400$-like wave. To this end we presented a new group of subjects with the same set of 160 sentences used in previous studies (Kutas and Hillyard, 1980a,b), but now $25 \%$ of them were completed at random with slides of complex, unrecognizable abstract drawings (Courchesne et al., 1975). The ERPs to these novel slides were compared with ERPs to the final words of the other sentences, all of which were semantically appropriate and of the expected size.

\footnotetext{
${ }^{a}$ Acknowledgments: This research was supported by grants NSF BNS80-05525 and Sloan B 1980-35. M. Kutas is supported by Research Scientist Development Award USPHS 1 KO2 MH 00322-01. We are grateful to E. Courchesne for providing us with the novel slides and $M$. $M$. Gortmaker for the manuscript and W. Borst for the figure preparations.
} 


\section{METHODS}

Six male adults (age range 18-27, five right-handed, one left-handed) participated in the experiment.

While the subjects reclined comfortably in an easy chair, slides containing single words or pictures were back-projected onto a translucent screen under the control of an electronic shutter. Stimulus sequences were created by advancing a carousel projector. Environmental sounds and noise from the projector and shutter were masked by white noise presented through headphones.

Scalp electrical activity was recorded using nonpolarizable electrodes from frontal $(\mathrm{Fz})$, central $(\mathrm{Cz})$, and parietal $(\mathrm{Pz})$ midline locations and from two temporo-parietal sites ( $\mathrm{W}_{1}$ and $\mathrm{W}_{2}$ ) situated laterally (by $30 \%$ of the interaural distance) and posteriorly (by $12.5 \%$ ) to the vertex. Eye movements were monitored via an electrode below the right eye and a bipolar supraorbital to external canthal montage. Trials contaminated with eye movements or blinks were excluded from the average ERPs. The acceptance rates of artifact free trials for the novels and semantically congruent words at the end of the sentences and for the control novel and word presentations were $81 \pm 7 \%, 76 \pm 8 \%, 64 \pm 11 \%$ and $62 \pm 11 \%$, respectively. Thus, in the averages of these trials, there was insignificant electro-ocular activity in either the vertical or horizontal eye monitoring channel. The three midline and the lower eye derivations were amplified with a bandpass of 0 to $40 \mathrm{~Hz}$. The bipolar L-EOG and the lateral scalp electrodes were amplified with a bandpass down $3 \mathrm{~dB}$ at 0.15 and $150 \mathrm{~Hz}$.

Data from all channels were stored on FM tape for off-line signal averaging with a PDP11/45 computer. A $1024 \mathrm{~ms}$ epoch of EEG data beginning $100 \mathrm{~ms}$ before the onset of each stimulus was analyzed at a sampling rate of $4 \mathrm{~ms}$ per point.

Each subject read 160 different seven-word sentences presented one word at a time. Subjects were instructed to read silently, "in order to answer questions about the contents of the sentences at the end of the experiment." A random 25\% of the sentences were completed by novel slides (all different) from the set used by Courchesne et al. (1975). Each sentence was forewarned with a slide containing XXXX and followed by a 2-second interval. Slides containing the words were flashed for $100 \mathrm{~ms}$ at a rate of one per second. After ten practice sentences were shown, 16 experimental blocks of ten sentences each were administered.

Following the completion of all the sentences, the subject was asked to look at the screen where either the word "station" or one of the novel slides was flashed repeatedly 80 times. For half of the subjects, the word was shown in the first run and the novel slide in the second run. For the remaining subjects the order of these conditions was reversed.

\section{RESULTS}

The grand average ERPs (across all subjects) elicited by the novel stimuli in the silent reading task are shown in the first column of FIGURE 1, superimposed on the ERPs elicited by the final (congruous) words in the other sentences. The same comparisons for each of the subjects at the midline electrode locations are provided in FIGURE 2. It is clear that the ERPs elicited by the final words in the sentences were distinctly different from the ERPs elicited by the novel slides in the same position. The novel ERPs in each subject were characterized by a large fronto-central negativity 
peaking between 250 and $350 \mathrm{~ms}$ and a large parietal positivity peaking between 400 and $600 \mathrm{~ms}$.

The latency of the negative peak to the novel slides averaged $320 \pm 8 \mathrm{~ms}$ at frontal sites. The $\mathrm{N} 320$ was largest over the frontal $(-12.9 \pm 2.8 \mu \mathrm{V})$ and central $(-11.4 \pm 2.9$ $\mu \mathrm{V})$ sites and was significantly smaller over the parietal scalp $(-4.2 \pm 2.5 \mu \mathrm{V})$. The N320 was significantly larger to novel slides $[F(1,5)=40.87, p<.001]$ than the negativity measured within approximately the same region in the ERPs elicited by the final words in the sentence, which averaged $-2.6 \pm 1.1 \mu \mathrm{V}$ across electrodes. In addition to this peaked negativity to the novel slides, four of the subjects showed a prolonged negativity over the frontal site coincident with the parietal positivity.

The positive component elicited over the posterior scalp by the novel stimuli was quite broad and peaked at around $530 \mathrm{~ms}$ at the parietal electrode. It was largest over the parietal regions $(17.6 \pm 2.5 \mu \mathrm{V})$ and became progressively smaller over central
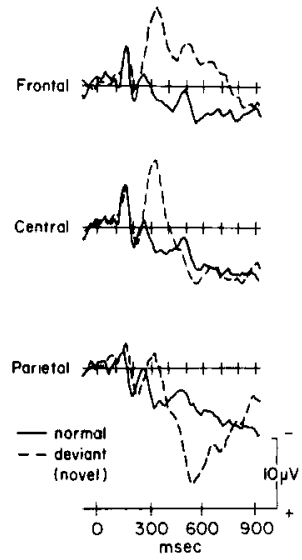
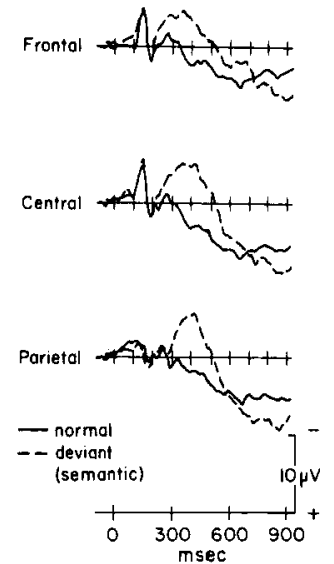
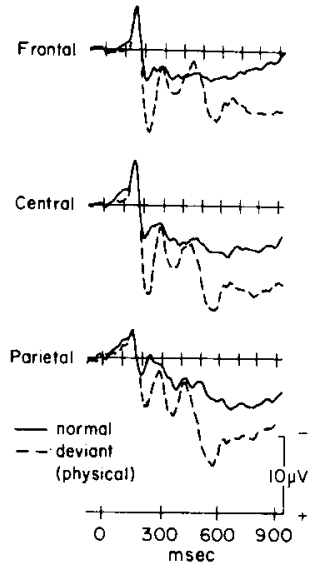

FIGURE 1. Column $I$ shows the comparison of the grand average ER.Ps (across all subjects) to the normal, semantically congruent seventh words and the deviant novel slides. $N=40$ /subject for novels and 100-120/subject for words. Columns 2 and 3 show grand average waveforms to semantically and physically deviant words, respectively. Data from Kutas and Hillyard, 1980a.

$(8.4 \pm 1.9 \mu \mathrm{V})$ and frontal $(-4.5 \pm 3 \mu \mathrm{V})$ sites [main effect of electrode, $F(2,10)=$ $24.68, p<0.001]$. The average amplitude of the ERP to the congruous final words (averaged across the three midline electrode locations) measured in the latency range of the P530 was $3.6 \pm 2.1 \mu \mathrm{V}$; this positivity was considerably smaller and differed in scalp distribution from the P530 elicited by the novel stimuli [condition by electrode interaction $F(2,10)=2.720, p<0.001$ ].

The ERPs elicited by the repeated presentations of the word "station" and one of the novel slides are shown in FigURE 3. Visual inspection of these waveforms indicates that the N320-P530 complex which differentiated the ERP to the novel stimuli from that to the terminal words in the sentences cannot be accounted for by the exogenous brain response to the physical features of the novel stimuli. Analyses of the ERP components elicited by these control stimuli revealed no significant differences between them in the 

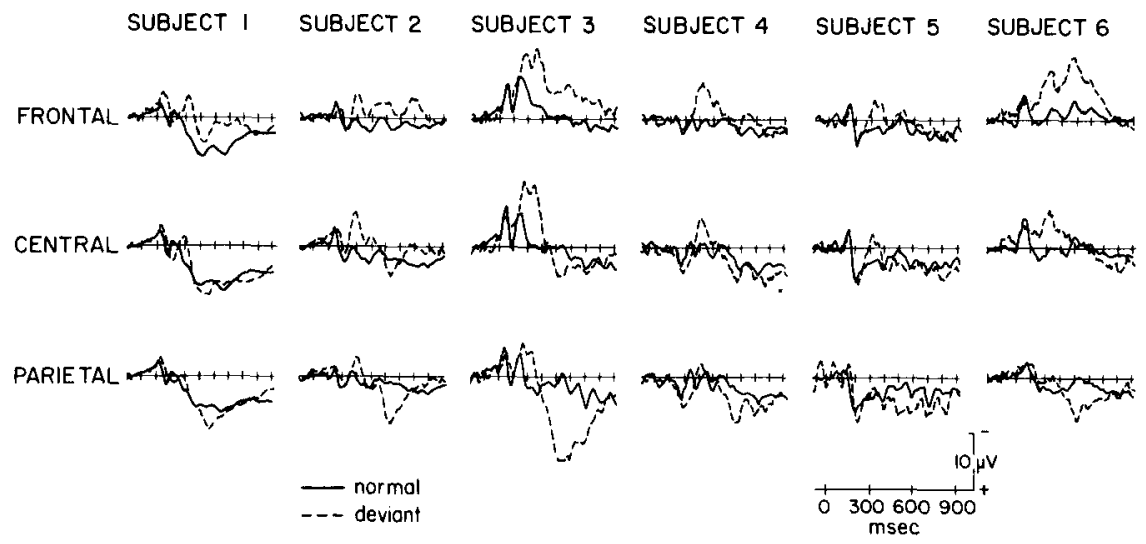

FIGURE 2. Comparison of the ERPs to the normal words and the deviant novel slides presented at the end of the sentences for each of the six subjects from the frontal, central, and parietal electrode locations.

$\mathrm{N}_{150,}$ P200, or N320 components. Neither control stimulus elicited a late parietal positivity.

As in our previous studies (Kutas and Hillyard, 1980b,c), there was a general tendency for the ERPs to the first through sixth words in the sentence to be laterally asymmetric on the scalp, with the left hemisphere being more positive in the region 400 to $700 \mathrm{~ms}$ poststimulus (left hemisphere area $=458 \pm 116 \mu \mathrm{V}$-ms versus right hemisphere area $=156 \pm 203 \mu \mathrm{V}$-ms). This difference, however, was not statistically significant; this may be due to the fact that two of the subjects had left-handers in their immediate family (see Kutas and Hillyard, 1980c).

FIGURE 3. Comparison of the grand average ERPs

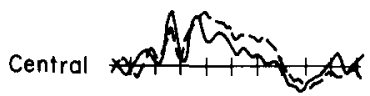
(across all subjects) elicited by the repeated presentations of a control word and a novel slide. ERPs are averaged over $28-71$ stimuli/subject.
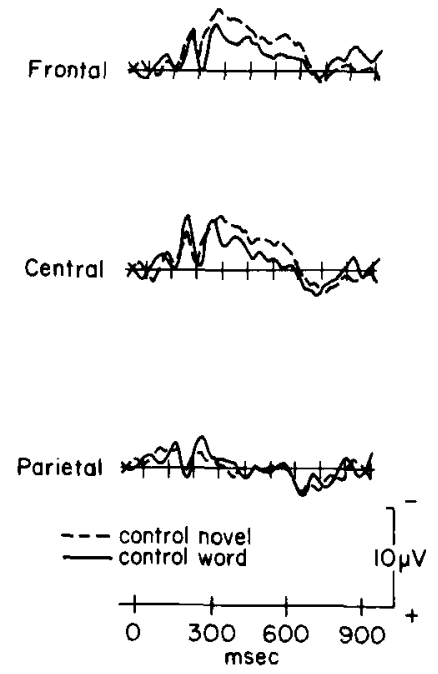


\section{DISCUSSION}

The novel stimuli in this silent reading situation elicited a series of ERP components which were clearly different from those associated with words that completed the sentences normally. Furthermore, this novel ERP differed considerably from the ERPs to either a semantic or a simple physical (e.g., word presented in large type) deviation within the same context as reported previously (Kutas and Hillyard, $1980 \mathrm{a}, \mathrm{b}, \mathrm{c})$. Thus, the N320 component to the novel slides differed from the centroparietal N400 elicited by semantic deviations (second column FIGURE 1) in being sharper, in having a shorter latency, and in displaying a more frontal scalp distribution. In fact, the distribution of the $\mathrm{N} 320$ component was remarkably similar to that of the visual evoked Niso component elicited by the stimuli in this experiment $(100 \%$ amplitude at $\mathrm{Cz}, 90 \%$ at $\mathrm{Fz}$ and $67 \%$ at $\mathrm{Pz}$ ).

The novel ERP also was differentiated from that elicited by words presented in large type (Kutas and Hillyard, 1980b), both in its late negative and positive components. The ERP to the large words (third column FIGURE 1) did not contain any sharp, frontal component comparable to the N320. Further, the late positivity elicited by the novel slide appears to consist primarily of a single component (P530), unlike the multipeaked positivity seen in association with the change in letter size. Moreover, the central/parietal amplitude gradient of the P530 was appreciably steeper than the LPC to the large type seventh words. Thus, while the Ps30 component most closely resembles the $\mathrm{P}_{300}$ or LPC in its properties, we cannot explain why its distribution is more posterior than that seen in other paradigms. Possibly, such differences arise from the degree of overlap with adjacent negative components.

The ERPs elicited by the novel slides in this reading task also differed dramatically from the ERPs elicited by these same stimuli when interspersed within a random series of the numbers " 2 " and "4" (Courchesne $e t$ al., 1975). In contrast to the N320-P560 complex seen here, occurrences of the novel slides in a stream of numbers were associated with a frontally distributed P300 component. Visual inspection of our data indicates that there is a hint of a positive component in the frontal ERPs at around 430 $\mathrm{ms}$ that appears to be distinct from the later, more parietal positivity. However, it is difficult to measure this component as it was superimposed upon the much larger frontal negativity. It may well be that the context in which a deviation occurs determines the nature of the brain's response to it.

These results indicate that the brain is differentially responsive to a wide variety of unexpected or deviant events in the environment, and that long latency ERPs are sensitive indices of these reactions. It appears that different classes of surprising events elicit distinctive ERP configurations that depend at least in part on the context in which they occur. Further work is required to specify the critical physical and psychological factors that determine which type of ERP complex will be elicited by different kinds of deviant events.

\section{REFERENCES}

Courchesne, E., R. Y. Courchesne \& S. A. Hillyard. 1978. The effect of stimulus deviation of $P_{3}$ waves to easily recognized stimuli. Neuropsychologia 16: 189-199.

Courchesne, E., S. A. HiLlyard \& R. Galambos. 1975. Stimulus novelty, task relevance and the visual evoked potential in man. Electroencephalogr. Clin. Neurophysiol. 39: 131-143.

Donchin, E., W. RitTer \& W. D. McCallum. 1978. Cognitive psychophysiology: The endogenous components of the ERP. In Event-Related Brain Potentials in Man. E. Callaway, P. Tueting, \& S. H. Koslow, Eds.: Academic Press. New York. 349-411. 
KuTAS, M. \& S. A. HiLlyARD. 1980a. Reading senseless sentences: Brain potentials reflect semantic incongruity. Science 207: 203-205.

KUTAS, M. \& S. A. HiLlyARD. 1980b. Reading between the lines: Event-related brain potentials during natural sentence processing. Brain and Language 11: 354-373.

KUTAS, M. \& S. A. HillyaRD. 1980c. Event-related brain potentials to semantically inappropriate and surprisingly large words. Biol. Psychol. 11: 99-116.

Picton, T. W., K. R. Camprell, J. Baribeau-Braun \& G. B. Proulx. 1978. The neurophysiology of human attention: A tutorial review. In Attention and Performance VIl. J. Requin, Ed.: Erlbaum. Hillsdale, New Jersey. 429-467.

RitTER, W., H. VAUGhAN, JR. \& L. COSTA. 1968. Orienting and habituation to auditory stimuli: A study of short term changes in averaged evoked responses. Electroencephalogr. Clin. Neurophysiol. 25: 550-560.

Roth, W. T. 1973. Auditory evoked responses to unpredictable stimuli. Psychophysiol. 10: 125138.

RoTH, W. T., J. M. FORD, S. J. LEWIS \& B. S. KOPELL. 1976. Effects of stimulus probability and task-relevance on event-related potentials. Psychophysiol. 13: 31 l-317.

RUCHKIN, D. S. \& S. SUTTON. 1978. Equivocation and P300 amplitude. In Multidisciplinary Perspectives in Event-Related Brain Potential Research. D. Otto, Ed.: U.S. Government Printing Office/EPA. Washington D.C. 175-177.

SNYDER, E. \& S. A. HILLYARD. 1976. Long-latency evoked potentials to irrelevant deviant stimuli. Behav. Biol. 16: 310-331.

Squires, K. C., E. Donchin, I. Herning \& G. MCCarthy. 1977. On the influence of task relevance and stimulus probability on event-related potential components. Electroencephalogr. Clin. Neurophysiol. 42: 1-14.

Squires, N. K., K. C. SQuires \& S. A. Hillyard. 1975. Two varieties of long-latency positive waves evoked by unpredictable auditory stimuli. Electroencephalogr. Clin. Neurophysiol. 38: $387-401$.

SUTtON, S., M. BraREN \& J. ZUBIN. 1965. Evoked potential correlates of stimulus uncertainty. Science 150: $1187-1188$. 